\title{
Social Sustainability: Perspectives on the Role of Manufacturing
}

\author{
Paola Fantini ${ }^{1}$, Marco Taisch ${ }^{2}$, and Claudio Palasciano ${ }^{2}$ \\ ${ }^{1}$ Fondazione Politecnico di Milano, \\ ${ }^{2}$ Politecnico di Milano, \\ Department of Management, Economics and Industrial Engineering, Milan, Italy \\ paola.fantini@fondazione.polimi.it, \\ \{marco.taisch, claudio.palasciano\}polimi.it
}

\begin{abstract}
The notion of social sustainability has been developed aiming at global growth. Policy makers have elaborated on this concept at regional and country level. Institutions and associations representing the scientific and technological environment have proposed their visions. Enterprises have adopted Corporate Social Responsibility practices. In this context, the role of manufacturing may have appeared so far limited to the specific aspects related to the workplaces. However, a broader perspective can lead to an extended awareness on how manufacturing can contribute to the social sustainability.
\end{abstract}

Keywords: social sustainability, sustainable manufacturing, human factors.

\section{Introduction}

The concept of sustainability emerged at the end of the eighties in the World Commission on Environment and Development report, which, instead of assessing the state of natural resources, highlighted possible ways to combine economic growth with environmental and societal issues. In particular, the following definition of sustainable development was provided: 'Development that meets the needs of the present without compromising the ability of future generations to meet their own needs' [1].

The "inter and intra-generational equity, the distribution of power and resources, employment, education, the provision of basic infrastructure and services, freedom, justice, access to influential decision-making fora and general 'capacity-building' have all been identified as important aspects of the development paradigm" according to the literature review on social sustainability examined in [2].

Sustainable development has become one of the main concern for policy makers at national and international level as well as the definition of appropriate frameworks for assessment. The problem of assessing social progress has been addressed in the Stiglitz report [3]: novel approaches have been proposed for measuring quality of life from an objective perspective, considering health, education, personal activities, political voice and governance, social connection, environmental conditions, personal insecurity, economic insecurity, but also from a subjective perspective and including a comprehensive assessment of inequalities. 
This paper illustrates how social objectives and concerns of policy makers have been reflected, interpreted and addressed by the manufacturing industry and propose an extended perspective and a roadmap for further research.

\section{State of the Art}

As sustainability has been recognized as a global challenge, public authorities, institutions and individuals representing the scientific, technological and industrial environment have started discussing how they should contribute to address this issue.

In [4], the American Association for the Advancement of Science recognized analyses shortfalls of sustainable well-being, identifying a set of topics in which science and technology have a significant role to play. CIRP has proposed a multilevel framework for proactively pursuing competitive sustainable manufacturing, involving industry, public authorities and academia, all the stake-holders at the global, supernational and national level [5], while the most recent trends and research challenges have been clearly outlined in [6].

At the macro level, the main stakeholders further elaborate on the themes of research, innovation and education as the key enablers for shaping the future, frequently adopting a participative approach, based on discussion and public consultations. The European Factory of the Future Research Association [7] has undertaken an open consultation on the proposed research roadmap, which includes several topics tightly related with social sustainability, increasing human achievements in future European manufacturing systems, creating sustainable, safe and attractive workplaces for Europe, creating sustainable care and responsibility for employees and citizens in global supply chains.

On different levels, scientists are developing new theories in order to better support from a theoretical viewpoint the integration of social sustainability in the disciplines and practices of manufacturing. A framework for increasing and assessing sustainability awareness among scientists has been developed as a contribution to better integrate sustainability concepts in production research activities [8].

Corporations have become aware of their environmental and social responsibilities, encouraged by regulators and media. Corporate Social Responsibility (CSR) practices have become more and more common, although often fragmented and disconnected from the business strategy. According to [9], "Addressing social issues by creating shared value will lead to self-sustaining solutions that do not depend on private or government subsides". Each company has to find the way most appropriate to its strategy.

In recent years, following to the well-known trends of globalization, transformation from vertical value chains to open value networks, web 2.0, crowdsourcing, dematerialization, virtualization and so on, management theory has developed new approaches which are more coherent with the emergent business and social landscape, leveraging the human factor along with technology enablers. Some researchers have recommended that management should evolve to foster trust and teamwork; to create a fluid, flexible, customized work community environment; to decompose vertical organizational structures towards inter-intra organizational networks with emergent new roles for facilitators and brokers; to create new exciting, entertaining and challenging workplaces for young people [10]. Others promote a cultural change as the solution to 
reinforce the companies' commitment towards more innovative ways to manage workforce, in a work-life integrated perspective [11].

Relations between organizational factors, individual psychological status and eventually behaviour have been studied for many years under different perspectives and facets. Although the picture is really complex and often fragmented, evidence of relations between contextual factors and individuals empowerment have been demonstrated [12]. In recent years, analysis on employees wellbeing highlights that more than in the past, individual have to deal with different objectives, desires, expectations and responsibilities, which can be clustered in two main categories of work and life. According to [13], "dual-centric experience" provides "more overall satisfaction, greater work-life balance, and less emotional exhaustion", that organization should take care of employees as whole individuals in order to enhance their wellbeing. Companies that implement policies in this sense, giving support for family responsibilities, improving employee health, leaving more time away from work, pursuing education and training, and supporting voluntarism appear to better perform on the financial side as well. Better performance can be related to the capability to attract and retain employees, to more effective behaviour of more satisfied employees, but also to better reputation of the company. Further studies [14] confirmed that line management support and trust is of the utmost importance to establish good relations with employees and thus subsequently favouring employee wellbeing at work.

In [15], the survey's results suggest that company should "create a workplace environment in which workgroup support takes place on a continuous basis. Moreover, managers should place greater relative emphasis on promoting and developing employees' organizational commitment given its high impact on favourable external representation behaviour. These actions will, ultimately, improve the company's performance."

With the increase of complexity and dynamicity of the business and manufacturing environment, and with automation and information technologies becoming more and more pervasive in the factory and in the supply chain, human intelligence knowledge and expertise is highly appreciated. The human-centricity has become a goal for the design and innovation as "the development of a product requires that always be taken into account the perspective of the people who build, maintain and operate it" [16]. "Meta-design theory emphasizes that future use can never be entirely anticipated at design time, as users shape their environments in response to emerging needs; systems should therefore be designed to adapt to future conditions in the hands of end users", as stated by [17]. This concept stands for end-users in domestic environments as well as for employees in a working environment, where co-designing and "human centerdness" are applied in organizational development settings [18]. According to [7] manufacturing is evolving from being perceived as a production-centric operation to a human-centric business with greater emphasis on workers, suppliers and customers in-the-loop". Manufacturing 2.0 [19] envisions "workers and managers alike given more opportunity for continuous development of skills and competences through novel knowledge-delivery mechanisms". The human centricity paradigms involves inclusion for young and elderly people: "Future enterprises will not only be better equipped for transferring skills to a new generation of workers but also proficient in assisting older workers with better user interfaces, intuitive user-experience-driven workflows and other aids, such as mobile and service robots. Furthermore, Manufacturing 2.0 enterprises would be equipped with interactive e-learning tools to facilitate 
students, apprentices and new workers gaining understanding of advanced manufacturing operations involving new ICT paradigms" [19].

\section{Dimensions of Social Sustainability}

Defining social sustainability objectives and their corresponding indicators is a challenging task a) due to the multilevel, multi-stakeholder and multifaceted nature of the addressed themes, b) due to the interaction with environmental, economic and institutional aspects, and, finally c) due to the uncertainty about the beliefs and models to be used as a reference. However, the need to monitor and steer sustainable development has challenged policy makers and the scientific and technological community to develop studies for the definition of applicable assessment methods and tools.

Papers, reports and literature reviews on social sustainability assessment, such as [20], [21], [22], [23], [24], [25], [26] [27], clearly show that priority is given to the definition of appropriate set of indicators as practical means to evaluate and compare performances either at macro and at micro level. However, there is a great fragmentation in the conceptual frameworks, so that different dimensions appear in alternative or intermingled lists, used to collect and group indicators. In general, the following limitations can be observed:

- lack of conceptual clarity in the definition of the dimensions to be assessed, with frequent confusion between impact categories (i.e. child labour, consume privacy), objectives (i.e. equal opportunities), subjects' implementation of policies (i.e. labour practices, respect of indigenous rights) stakeholders groups (i.e. workers, consumers);

- $\quad$ shortfall in the identification of the stakeholders;

- poor awareness and representation of the relationships and inter-linkage among and within the dimensions and the indicators.

In the available schemas indicators have been set in relationship with each of the different dimensions, relevant for manufacturing social sustainability, as illustrated in Figure 1, but the interdependencies among these dimensions have not been explicated.

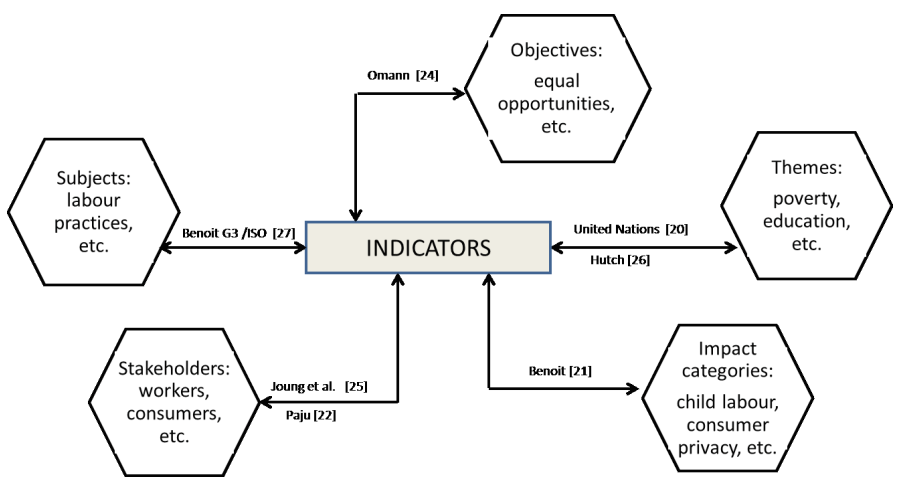

Fig. 1. Dimensions of social sustainability in relationship with indicators 


\section{Perspectives for Developing a Social Sustainability Roadmap for Manufacturing}

Considering the complexity of the subject, in order to overcome the existing issues and better support the progress of social sustainability in manufacturing, a research roadmap is needed. To the authors' judgement, future research will have to thoroughly investigate the complex network of cause-effect relationships and interactions that connect manufacturing and its performances to the sustainability themes, as represented in the simplified schema of Figure 2. In particular, research should address the following topics.

- The definition of relevant categories for social sustainability to be used in relationship with the manufacturing impact on the different classes of roles and stakeholders. These categories should represent the end-point impact of manufacturing, instantiating the sustainability themes defined by policy makers.

- The identification of the relevant eco-system roles and stakeholders, considering all the types of interactions that an industrial enterprise directly or indirectly may establish with individuals, associations, private and public institutions. These roles and stakeholders should constitute the mid-point nodes in which to assess the manufacturing impact.

- The analysis of the effects that manufacturing strategies, policies and practices induce on the eco-system roles, taking into account mutual interactions and interdependencies in the eco-system, and the social and financial implications.

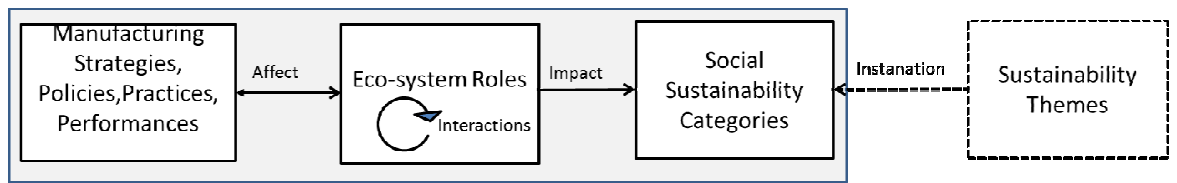

Fig. 2. Manufacturing and Social Sustainability simplified cause-effect relationships

In fact, all the decisions and actions made by manufacturing enterprises create different types of interaction with one or more roles in the eco-systems, even directly or indirectly, by triggering other players' actions and reactions, as illustrated by the following examples.

- Policies for recruiting, retaining and managing human resources obviously affect internal staff, but also actual or potential candidates for jobs, all their families, other legal entities offering jobs. In addition, policies concerning education/specialization entry levels and training may influence schools and universities to the extent to trigger the creation of special courses, in some cases in collaboration with the manufacturing enterprise.

- Health, postural, dietary, hygiene programs, screening or caring services offered or incentivized for employees and their families can affect health care systems and contribute to increase health standards in the populations.

- Environmental monitoring systems set up and managed by a factory may interact with local authorities supervision and contribute to increase safety and security of 
the surrounding inhabitants. Furthermore, emergency and disaster recovery plans involving manufacturing staff and equipment might be programmed in collaboration with other institutions and agencies, providing additional environmental and social benefits.

- $\quad$ Procurement policies, supplier evaluation and management can affect local workers, such as service providers' staff employed for ancillary activities in the factories, such as cleaning, packaging, logistics, their health and safety conditions, rights and fair wages as well as the more extensively analysed supply chain employees and their environment, in foreign countries.

- Criteria and procedures for product and service design, marketing and delivery can affect customers health, life style, privacy, but can also impact other roles in the value networks, such as providers for maintenance or application services or end of life operators, who may be favoured, hindered or endangered in their economic and social activities and relationships.

- Involvement and engagement in activities aiming at influencing industrial research, education programs and policies through different forms of association and participation can also shape the future of manufacturing towards more sustainable development.

Manufacturing has traditionally pursued economic, quality, service and flexibility performances. Sustainability objectives have often been superimposed rather than integrated in the corpus of existing theories and practices. Further research is necessary to better understand all the social implications of manufacturing-related processes, decision making, behaviours and the interplay with business and economic results.

To the opinion of the authors, a research roadmap should aim at the definition of a manufacturing sustainability reference model, as the illustrative example of Figure 3, to be used for the analysis, evaluation and revision of the manufacturing theories and practices in order to better assess and improve social sustainability.

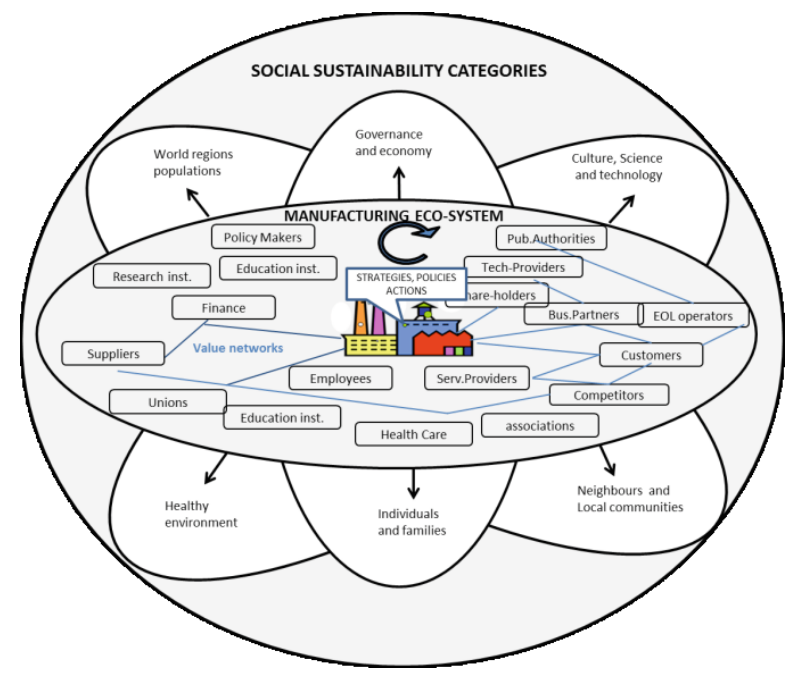

Fig. 3. Dimensions of social sustainability in relationship with indicators 
Future research should leverage existing literature from different disciplines, but also evidence from the field, experts judgement, case studies and should address methods and tools to assess and prioritize the types of strategies, policies and actions with higher potential impact on social sustainability categories, as well as viable economic and financial performances. Main achievements should lead to the definition of manufacturing specific policies, indicators frameworks, codes of conducts and principles, guidelines, to support pursuing and assessing social sustainability.

\section{Conclusions and Outlook}

The knowledge about manufacturing specific current and potential role versus social sustainability is still limited to the main and most evident aspects. Further research is needed to extend the perspective and achieve greater awareness of the different ways in which social sustainability can be pursued through interactions with all the roles and stakeholders of the manufacturing ecosystem.

The authors proposed an approach for a research roadmap that may lead to a reference model, methods and tools to better guide and strengthen the contribution of manufacturing to the global objective of an inclusive and sustainable development.

Acknowledgements. This paper has been developed in the perspective of the research project SO SMART, funded by the European Commission within FP7 (608734).

\section{References}

[1] WCED, Our common future: the Bruntland report. Oxford University Press, New York (1987)

[2] Vallance, S., Perkins, H.C., Dixon, J.E.: What is social sustainability? A clarification of concepts. In: Geoforum 2011 (2011)

[3] Stglitz, J.E., Sen, A., Fitoussi, J.-P.: Report by the Commission on the Measurement of Economic Performance and Social Progress (2009)

[4] Holdren, J.P.: Science and technology for sustainable well-being. Science - Published by AAAS, 424-434 (2008)

[5] Jovane, F., Yoshikawa, H., Alting, L., Boer, C.R., Westkamper, E., Williams, D., Tseng, M., Seliger, G., Paci, A.M.: The incoming global technological and industrial revolution towards competitive sustainable manufacturing. CIRP Annals - Manufacturing Technology (2008)

[6] Garetti, M., Taisch, M.: Susteinable manufacturing: trends and research challenges. Production Planning \& Control: The Management of Operations, 83-104 (2012)

[7] EFFRA, Factories of the Future PPP - FoF20220 Roadmap - Consultation document, Bruxelles (2012)

[8] Johansson, B., Dagman, A., Rex, E., Nyström, T., Knutson Wedel, M., Stahre, J., Söderberg, R.: Sustainable production research: awareness, masures and development. IntlJournal-Sustainable-Development (2012)

[9] Porter, M.E., Kramer, M.R.: The Lonk Between Competitive Advantage and Corporate Social Responsibility. Harvard Business Review (2006) 
[10] McDonald, P.: It's time for management version 2.0: Six forces redefining the future of modern management. Futures, 797-808 (2011)

[11] Harrington, B., Ladge, J.J.: Present Dynamics and Future Directions for Organizations. Organizational Dynamics, 148-157 (2009)

[12] Siegall, M., Gardner, S.: Contextual factors of psychological empowerment. Personnel Review, 703-722 (2000)

[13] Bourne, K.A., Wilson, F., Lester, S.W., Kickul, J.: Embracing the whole individual: Advantages of a dual-centric perspective of work and life. Business Horizons, 387-398 (2009)

[14] Baptiste, N.R.: Tightening the link between employee wellbeing at work and performance: A new dimension for HRM. Management Decision, 284-309 (2008)

[15] Lages, C.R.: Employees' external representation of their workplace: Key antecedents. Journal of Business Research (2012)

[16] Mavrikios, D., Karabatsou, V., Pappas, M., Chryssolouris, G.: An efficient approach to human motion modeling for the verification of human-centric product design and manufacturing in virtual environments. Robotics and Computer-Integrated Manufacturing, 533-543 (2007)

[17] Maceli, M., Atwood, M.: From Human Factors to Human Actors to Human Crafters. In: iConference, Seattle (2011)

[18] Kronqvist, J., Salmi, A.: Co-Designing (with) Organizations -Human-Centeredness, Participation and Embodiment in Organizational Development (2012)

[19] Majumdar, A., Szigeti, H.: ICT for Manufacturing - The ActionPlanT Vision for Manufacturing 2.0. ActionPlanT (2011)

[20] United Nations, Indicators of Sustainable Development: Guidelines and Methodologies, United Nations, New York (2007)

[21] Benoit-Dorris, C.: Developing Social Sustainability Metrics. In: Roundtable on Social Impacts of the Electronics Sector, Berkeley

[22] Paju, M., Heilala, J., Hentula, M., Heikkila, A., Johansson, B.: Framework and indicators for a sustainable manufacturing mapping methodology. In: Winter Simulation Conference (2010)

[23] Feng, S.C., Joung, C.-B.: An Overview of a Proposed Measurement Infrastructure for Sustainable Manufacturing Metrics. In: The 7th Global Conference on Sustainable Manufacturing (2009)

[24] Omann, I., Spangenberg, J.H.: Assessing Social Sustainability. In: 7th Biennal Conference of the International Society for Ecological Economics, Wien (2002)

[25] Joung, C.B., Carrell, J., Sarkar, P., Feng, S.C.: Categorization of indicators for sustainable manufacturing. Ecological Indicators (2012)

[26] Hutchins, M.J., Sutherland, J.W.: An exploration of mesures of social sustainability and their application to supply chain decisions. Journal of Cleaner Production (2008)

[27] Benoit, C., Vickery-Niederman, G.: Social Sustainability Assessment Literature Review, The Sustainability Consortium, Arizona State University, and University of Arkansas (2011) 